\title{
CARACTERIZAÇÃO DOS RECURSOS HÍDRICOS SUBTERRÂNEOS NO MUNICÍPIO DE SANTA ROSA - RS
}

\author{
Eduardo Samuel Riffel ${ }^{1}$ \\ Jose Luis Silverio da Silva ${ }^{2}$
}

\begin{abstract}
Resumo: A água é um recurso natural essencial à vida, por isso se faz necessário que se haja um conhecimento amplo sobre sua quantidade e qualidade. Este trabalho apresenta uma análise das águas subterrâneas no município de Santa Rosa localizado no estado do Rio Grande do Sul. Tendo como objetivo principal caracterizar os recursos hídricos subterrâneos do município através de uma espacialização cartográfica, realizar uma avaliação das características físico-químicas e hidrodinâmicas das águas subterrâneas, e cadastrar os poços tubulares na área urbana e rural. Para tanto, utilizou-se para a execução do estudo, dados pré-existentes na página eletrônica do Sistema de Informações de Águas Subterrâneas (SIAGAS), na Prefeitura Municipal de Santa Rosa, e em empresas de perfuração de poços, realizou-se também pesquisa de campo com o uso do "Global Position System" (GPS) e técnicas computacionais. Para caracterizar as águas subterrâneas, fez-se a análise de parâmetros físico-químicos em amostras coletadas em campo. Como resultado mais relevante desta pesquisa tem-se o cadastro dos poços tubulares para um possível monitoramento e a geração de diversos mapas indicando a espacialização da qualidade da água. Desta forma, esse estudo contribuirá para o planejamento adequado do município de Santa Rosa-RS trazendo subsídios aos órgãos gestores e à sociedade.
\end{abstract}

Palavras-Chave: Recursos Hídricos Subterrâneos; parâmetros físico-químicos; Sistema Aqüifero Serra Geral; mapeamento.

\section{ANALYSIS OF GROUDWATER RESOURCES IN THE MUNICIPALITY OF SANTA ROSA - RS}

Abstract: Water is a natural resource essential to life, so it is necessary that there is a broad knowledge about their quantity and quality. This paper presents an analysis of groundwater in the Santa Rosa state Southern Brazil. Its main goal is to characterize the groundwater resources of the municipality through a spatial map, conduct an assessment of the physicochemical and hydrodynamic groundwater. Were registered their wells in urban and rural areas. Were used to carrying out the study, pre-existing data on the website of the Groundwater Information System (SIAGAS), the prefecture of City of Santa Rosa. Were executed contacts with the companies well drilling and was carried out also field research with the use of Global Position System (GPS) and computational techniques. To characterize the groundwater, was executed the analysis of physical and chemical parameters in samples collected in the field. As most relevant result of this research has been the registration the position wells for a possible monitoring and generation of several maps showing the spatial distribution of water quality. Thus, this study will contribute to the proper planning of the municipality of Santa Rosa bringing benefits to governing bodies and society.

\footnotetext{
${ }^{1}$ Bacharel em Geografia e Mestrando em Geografia pela Universidade Federal do Rio Grande do Sul - UFRGS - E-mail: edriffel@gmail.com ${ }^{2}$ Geólogo, Doutor em Geociências e Professor do Departamento de Geografia da Universidade Federal de Santa Maria - UFSM - E-mail: silverioufsm@gmail.com

DOI: 10.7154/RDG.2011.0022.0001
} 
Key-Words: Groundwater Resources; physical and chemical parameters; Aquifer System Serra Geral; mapping.

\section{INTRODUÇÃO}

A crescente urbanização e o surgimento de novas técnicas e novas necessidades humanas, fazem com que o homem interfira na natureza, tentando suprir suas necessidades através dos meios naturais. Um dos recursos mais atingido é a água, que é indispensável à manutenção dos ecossistemas, e uma das principais necessidades humanas.

A água se encontra em praticamente todos os lugares e é considerada a substância mais abundante do planeta, pois recobre $2 / 3$ da superfície terrestre. No entanto, cerca de $97,5 \%$ do total de água na Terra é salgada. Menos de 2,5\% são doces e estão distribuídas entre as calotas polares $(68,9 \%)$, os aqüíferos $(29,9 \%)$, os rios e lagos $(0,3 \%)$ e outros reservatórios (0,9\%). Assim, apenas $1 \%$ da água doce pode ser aproveitada pela humanidade, o que representa 0,007\% de toda a água do planeta (Hirata, 2000).

Os aqüíferos são considerados a grande promessa para uma futura escassez de água doce no planeta, no entanto pouco se sabe sobre as suas reais proporções, potencialidades e fragilidades, e ainda muitas vezes ocorre um uso desenfreado e inconseqüente desses recursos. Diversas pessoas perfuram poços tubulares clandestinos, que não obedecem às normativas, e que podem provocar contaminações. Uma vez atingido o lençol freático, pode provocar danos de grandes proporções as águas subterrâneas, ao meio e aos usuários. Por isso se faz necessário um maior conhecimento dos recursos subterrâneos e dos pontos existentes de extração (poços tubulares, escavados ou nascentes), os estudos preliminares de cadastro se constituem menos onerosos do que uma possível recuperação posterior do aqüífero se este for contaminado.

A avaliação qualitativa e quantitativa, do aproveitamento e da exploração dos recursos hídricos subterrâneos no município de Santa Rosa-RS, tem grande importância no planejamento do suprimento da demanda de água visando atender as necessidades de água das populações urbanas frente ao incremento da demanda devida à expansão da malha urbana.

As águas subterrâneas, como reserva estratégica face aos seus aspectos naturais de proteção, são de primordial importância no abastecimento do suprimento público em toda região. 
Neste sentido, o presente trabalho teve como objetivo geral caracterizar as captações das águas subterrâneas do município de Santa Rosa, através de uma espacialização cartográfica de suas características principais, como qualidade e localização. A partir de dados préexistentes e de trabalhos de campo, pretende-se trazer subsídios aos órgãos gestores municipais e à sociedade civil, na busca de um uso consciente e racional das águas subterrâneas no município.

\section{Localização do município de Santa Rosa-RS}

O município de Santa Rosa possui 65.016 habitantes, dos quais 55.950 vivem na área urbana e 9.066 na área rural. Este foi emancipado em 10 de julho de 1931, e faz parte da Microrregião Geográfica que leva o seu nome, localizada na porção noroeste do estado (figura 1).

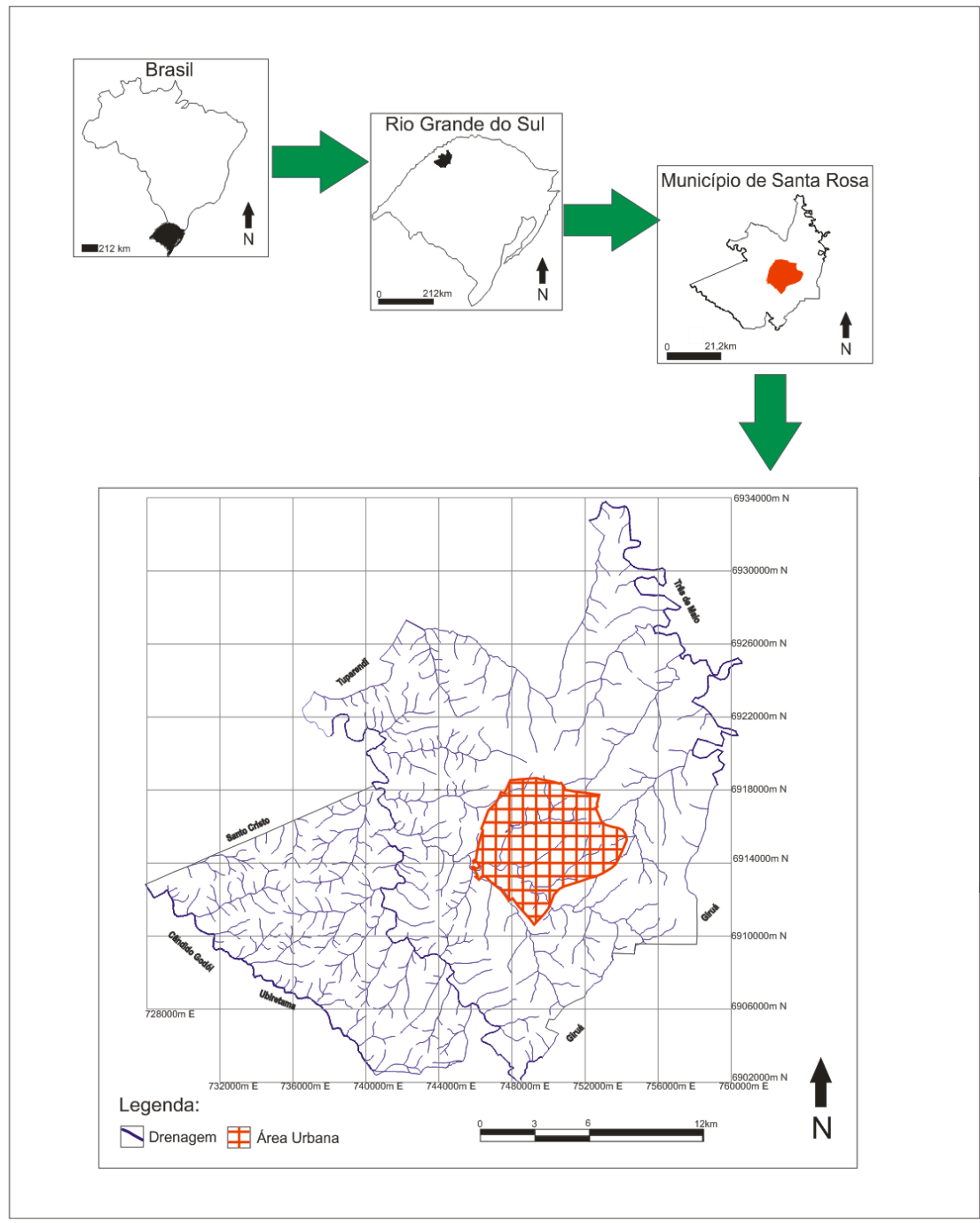

Figura 1 - Mapa de Localização do município de Santa Rosa-RS. Fonte: Plano Diretor Municipal, 2006. 


\section{Aspectos físicos do município de Santa Rosa-RS}

A rocha predominante no município de Santa Rosa-RS é o Basalto, rocha extrusiva vulcânica. Proveniente da decomposição dessa rocha básica, se originam solos caracterizados pela coloração vermelha escura, que possuem um perfil profundo e boa drenagem natural, a cor avermelhada é devido ao elevado teor de óxido de ferro contido nas rochas basálticas.

Hausman (1995) subdividiu o Estado do Rio Grande do Sul em quatro províncias litológicas, sendo que o município de Santa Rosa está localizado na província do Escudo, que é caracterizado por uma coluna estratigráfica sedimentar que vai do Carbonífero ao Cretáceo, formada por sedimentos epicontinentais e terrígenos. Baseado na morfologia do relevo, o mesmo autor classificou o estado em Províncias Geomorfológicas, classificando o município na Província Geomorfológica do Planalto.

A região faz parte da Bacia Sedimentar do Paraná constituída por rochas vulcânicas básicas basaltos, Carraro et al. (1974). Estas rochas vulcânicas capeiam as rochas sedimentares porosas penetradas na perfuração de um poço tubular, Corner (1995). A capa de rochas vulcânicas da Formação Serra Geral penetrou 1.115 m. Os arenitos da Formação Botucatu foram penetrados entre 1.155 e 1.220 m. Conforme o Sistema Brasileiro de Classificação dos solos (1999) da Embrapa, a região apresenta três tipos de solos: Latossolo Vermelho Distroférrico, Chernossolo Argilúvico Férrico e o Neossolo Litólico Eutrófico.

O município de Santa Rosa está localizado na Bacia Hidrográfica Turvo - Santa Rosa - Santo Cristo U-30, que se situa a Norte - Noroeste do Estado do Rio Grande do Sul, entre as coordenadas geográficas $27^{\circ} 07^{\prime}$ a $28^{\circ} 13^{\prime}$ de latitude Sul e $53^{\circ} 24^{\prime}$ a $55^{\circ} 20^{\prime}$ de longitude Oeste. Possui uma área de 11.056,23 km², abrangendo municípios como Horizontina, ljuí, Porto Xavier, Santa Rosa, Santo Ângelo e Três de Maio, com população estimada em 371.199 habitantes. Os principais cursos de água são os rios Turvo, Santa Rosa, Santo Cristo, Amandaú e Comandai. Os principais usos da água se destinam a dessedentação animal, abastecimento humano, irrigação, e para produção de energia elétrica, esses rios possuem um curso sinuoso e com desnível altimétrico, apresentando diversas quedas d'água de pequena envergadura.

Segundo Hausman (1995) a temperatura média anual do município encontra-se na faixa de 19 a 20 ㄷ , enquanto que a precipitação média é de aproximadamente $1800 \mathrm{~mm}$ por ano. $\mathrm{A}$ classificação climática segundo Koeppen é caracterizada pelo Cfah que consiste num clima subtropical com invernos moderados. 


\section{Recursos Hídricos Subterrâneos e seu uso}

Ao tratar-se de águas subterrâneas é fundamental considerar o conceito de aqüífero' que segundo a Resolução №. 15/ 2001 do CNRH é entendido como o corpo hidrogeológico com capacidade de acumular e transmitir água através de seus poros, fissuras ou espaços resultantes da dissolução e carreamento de materiais rochosos. Tucci et al. (1993, p. 289) por sua vez defendem que aqüífero “(...) é uma formação geológica (ou um grupo de formações) que contém água e permite que a mesma se movimente em condições naturais e em quantidades significativas".

Segundo Rebouças (1999) os aqüíferos são corpos rochosos que se caracterizam pelas condições relativamente favoráveis à circulação e armazenamento de água subterrânea. As águas provenientes dos aqüíferos apresentam fatores vantajosos à exploração, já que estas não apresentam a necessidade de uso de processos de purificação e de tratamento de altos custos. Isto ocorre devido ao simplificado processo pelo qual passam na maior parte das vezes, e ainda devido à disposição, quantidade e qualidade destas águas e seu acesso facilitado.

Por outro lado a Portaria no 518/2004 que normatiza o consumo humano de água exige que seja executado o tratamento das captações, especialmente as fontes alternativas onde estão incluídos os poços (tubulares, escavados e /ou nascentes).

A área de estudo encontra-se sobre uma das maiores reservas de águas subterrâneas do Planeta, o Sistema Aqüífero Guarani, PSAG (2009). Este está protegido por uma espessa capa de rochas vulcânicas extrusivas pertencentes à Formação Serra Geral a qual forma o Sistema Aqüífero Serra Geral.

As pesquisas revelaram que a captação de água mais profunda no Estado do Rio Grande do Sul ocorre em Santa Rosa e é utilizado para fins industriais CORNER (1995).

Em relação aos usos de águas subterrâneas estima-se que existam no país pelo menos 400 mil poços (Zoby; Matos, 2002). A água de poços e fontes vem sendo utilizada intensamente para diversos fins, tais como abastecimento humano, irrigação, indústria e lazer. No Brasil, 15,6\% dos domicílios utilizam exclusivamente água subterrânea (IBGE, 2009). Embora o uso do manancial subterrâneo seja complementar ao superficial em muitas regiões, em outras áreas do país a água subterrânea representa o principal manancial hídrico. Ela desempenha importante papel no desenvolvimento socioeconômico do país. 
A informação sobre a qualidade das águas subterrâneas no país existe de forma dispersa e está concentrada, principalmente, nos aqüíferos localizados próximo às capitais. Há carência de estudos sistemáticos sobre os aqüíferos em um contexto regional e sobre a qualidade química e microbiológica de suas águas.

\section{Aspectos legais}

Mesmo havendo leis e programas específicos que tratam de águas subterrâneas, e ainda sendo instituída a Câmara Técnica Permanente de águas subterrâneas segundo o Decreto no 2.612 de 3 de junho de 1998, que tem entre suas competências propor mecanismos de proteção e gerenciamento de águas subterrâneas, ainda existe pouco conhecimento por parte da população e pouco interesse por parte do poder público em fiscalizar o uso dos recursos hídricos subterrâneos, pois segundo o Código Estadual do Meio Ambiente, lei 11.520/2000, Art. 134 que: "Incumbe ao poder público manter programas permanentes de proteção das águas subterrâneas, visando ao seu aproveitamento sustentável, e a privilegiar a adoção de medidas preventivas em todas as situações de ameaça potencial a sua qualidade".

O Art. 136 da mesma lei expõe que os recursos hídricos subterrâneos devem constar nos planos diretores:

Na elaboração de Planos Diretores e outros instrumentos de planejamento urbano deverão ser indicados:

I-A posição de lençóis de águas subterrâneas vulneráveis;

II - As áreas reservadas para o tratamento e o destino final das águas residuárias e dos resíduos sólidos, quando couber.

Parágrafo único - O órgão ambiental deverá manifestar-se sobre as áreas reservadas mencionadas no inciso II deste artigo, observada a legislação vigente (SEMA, 2000).

E o Art. $134, \S 2^{\circ}$ da mesma lei fala que:

A vulnerabilidade dos lençóis d'água subterrâneos será prioritariamente considerada na escolha da melhor alternativa de localização de empreendimentos de qualquer natureza potencialmente poluidores das águas subterrâneas (SEMA,2000).

Ainda segundo consta no 5 o item do Art. 49 do conjunto de normas legais do Conselho Nacional de Recursos Hídricos, constitui infração das normas de utilização de recursos hídricos superficiais ou subterrâneos: "perfurar poços para extração de água subterrânea ou operá-los sem a devida autorização;" 
Visando manter a qualidade d'água subterrânea, e manter os poços protegidos da poluição, a SEMA (Secretaria Estadual do Meio Ambiente) normatizou a outorga de poços, através do decreto $n^{\circ} 42.047 / 2002$, Art. 30, o qual exige a presença de selo sanitário em concreto junto à "boca do poço", a instalação de tubo-guia com diâmetro de 2 polegadas em plástico PVC para medições do nível d'água e a instalação de hidrômetro para aferição da vazão e do consumo diário ou mensal, de acordo com a vazão e o consumo. Esse decreto exige também o cercamento de uma área, com raio de dez metros a contar da "boca do poço" como Perímetro imediato de Proteção Sanitária.

Dessa forma se faz necessário que haja por parte das esferas públicas nacional, estadual e municipal um maior interesse por parte da conservação e conscientização da população em relação aos usos das águas subterrâneas. Pois segundo Foster e Hirata (1988), gerenciar a utilização de águas subterrâneas significa propor políticas que garantam que os aqüíferos sejam fontes seguras e confiáveis de abastecimento de água. Esse fato implica em especial preocupação com a proteção dos aqüíferos devido à dificuldade e a impraticabilidade de se promover à remoção de poluentes de fontes pontuais de captação (poços) e também, ao fato de que a reabilitação de um aqüífero poluído requer um custo muito elevado.

Deve-se ter uma preocupação especial também em relação à qualidade das águas subterrâneas, obedecendo às normativas de qualidade de água. A Portaria no 518/2004 do Ministério da Saúde estabelece os Valores Máximos Permissíveis (VMP) para a saúde humana em relação ao consumo de água (Quadro 1).

\begin{tabular}{|c|c|c|}
\hline Parâmetro & Unidade & VMP \\
\hline Alumínio & $\mathrm{mg} / \mathrm{L}$ & 0,2 \\
\hline Amônia (como $\mathrm{NH}_{3}$ ) & $\mathrm{mg} / \mathrm{L}$ & 1,5 \\
\hline Cloreto & $\mathrm{mg} / \mathrm{L}$ & 250 \\
\hline Ferro & $\mathrm{mg} / \mathrm{L}$ & 0,3 \\
\hline Manganês & $\mathrm{mg} / \mathrm{L}$ & 0,1 \\
\hline Sódio & $\mathrm{mg} / \mathrm{L}$ & 200 \\
\hline Sólidos dissolvidos totais & $\mathrm{mg} / \mathrm{L}$ & 1.000 \\
\hline Sulfato & $\mathrm{mg} / \mathrm{L}$ & 250 \\
\hline Sulfeto de Hidrogênio & $\mathrm{mg} / \mathrm{L}$ & 0,05 \\
\hline Zinco & $\mathrm{mg} / \mathrm{L}$ & 5 \\
\hline Fluoreto & $\mathrm{mg} / \mathrm{L}$ & 1,5 \\
\hline Nitrato & $\mathrm{mg} / \mathrm{L}$ & 10 \\
\hline
\end{tabular}

Quadro 1 - padrão de potabilidade de água para consumo humano. Fonte: portaria no 518/2004 do Ministério da Saúde. 


\section{Sistemas Aqüíferos e Domínios Hidrogeológicos}

Machado e Freitas (2005) utilizaram o conceito de Unidades hidroestratigráficas subdividindo o Estado do Rio Grande do Sul em 21 Sistemas Aquiferos na escala de 1:750.000, estando Santa Rosa no Sistema Aqüífero Serra Geral I, considerado um aqüífero de baixa capacidade específica tendo sua produtividade entre 0,5 e $2 \mathrm{~m}^{3} / \mathrm{h} / \mathrm{m}$. Estes sistemas consideram os aqüíferos, os aquitardos e os aquicludes.

Numa escala de menor detalhe, de 1:2.500.000 a CPRM (2007) utilizou o conceito de Domínios e Subdomínios hidrogeológicos. Estes foram assim classificados:

1- Formações Cenozóicas;

2- Bacias Sedimentares;

3- Poroso/Fissural;

4- Metassedimentos/Metavulcânicas;

5- Vulcânicas;

6- Cristalino;

7- Carbonatos/Metacarbonatos.

No município de Santa Rosa tem-se a ocorrência principal do Domínio Vulcânico caracterizado pelas rochas vulcânicas que compõem o Sistema Aqüífero Serra Geral (SASG), e dois tipos aquiferos (Plano Nacional de Recursos Hídricos, 2006):

- Fissural: a água está associada à presença de descontinuidades na rocha, responsáveis por uma porosidade secundária associada a falhas, fraturas e diáclases. É representado pelas rochas ígneas e metamórficas e ocupa cerca de $4.600 .000 \mathrm{~km}^{2}$, que equivalem a $54 \%$ do território nacional. 0 aqüífero fraturado apresenta, em geral, sistemas aqüíferos com potencial hídrico inferior àqueles pertencentes aos tipos Fraturado, Cárstico e Poroso. O Sistema Aqüífero Serra Geral é do tipo fraturado, possui uma área aflorante de cerca de $412.000 \mathrm{~km}^{2}$ e espessura média de $150 \mathrm{~m}$. Ocorre recobrindo as formações paleozóicas da bacia do Paraná e confinando o Sistema Aqüífero Guarani. Em direção ao centro da bacia, alcança espessura de $2.000 \mathrm{~m}$. Os poços explotados têm profundidades médias de $123 \mathrm{~m}$ e vazão média de $23 \mathrm{~m}^{3} / \mathrm{h}$. Em geral os poços localizados no município de Santa Rosa pertencem à Formação Serra Geral, com exceção de um poço tubular profundo que extrai água do Aqüífero Guarani, Corner (1995).

- Poroso: a água está contida entre os grãos que compõem a rocha (porosidade primária ou porosidade residual). Esse tipo de aqüífero é representado pelas rochas 
sedimentares, como os arenitos e conglomerados. De forma geral, apresenta o maior potencial hídrico. Ocupa uma área de cerca de $3.500 .000 \mathrm{~km}^{2}$, equivalente a $41 \%$ do território nacional. Ele inclui os aqüíferos de maior vocação hídrica no país e está situado nas bacias sedimentares. As maiores bacias sedimentares brasileiras são a do Paraná, do Parnaíba e do Amazonas. Na Bacia do Paraná encontra-se o Sistema Aqüífero Guarani, que se estende por uma área de aproximadamente $1.195 .000 \mathrm{~km}^{2}$, no Brasil, na Argentina, no Paraguai e no Uruguai. Cerca de $71 \%$ desse total está no Brasil. No território nacional, esse sistema ocorre no subsolo de oito Estados e em quatro regiões hidrográficas: Paraguai, Tocantins, Paraná e Atlântico Sul, PSAG (2009).

Sua espessura varia entre 200 e 800 m, com um valor médio de $250 \mathrm{~m}$. Cerca de $90 \%$ do sistema aqüífero é confinado. Alguns milhares de poços já perfurados têm profundidades entre 300 e $1.500 \mathrm{~m}$. As vazões variam de 50 a $1.000 \mathrm{~m}^{3} / \mathrm{h}$, com predominância de valores entre 100 e $500 \mathrm{~m}^{3} / \mathrm{h}$, ou seja, suficiente para abastecer entre 10 mil e 50 mil pessoas por poço. Apesar de o consumo atual, em nível regional, se situar abaixo da recarga anual, vários municípios já apresentam sinais de superexplotação, notadamente como é o caso de Ribeirão Preto-SP que possui cerca de 500 mil habitantes abastecidos com água subterrânea, tendo como principal manancial o Aqüífero Guarani. ${ }^{2}$

Apesar do grande potencial de água subterrânea no país, predomina a proliferação indiscriminada de poços, que são freqüentemente mal construídos e não seguem normas técnicas. A explotação dos sistemas aqüíferos é feita de forma descontrolada. Esse fato tem comprometido seriamente as águas subterrâneas em termos de qualidade e quantidade. Localmente já existem indícios de superexplotação em sistemas aqüíferos importantes, além de que, em algumas regiões, por causa das elevadas altitudes, sua captação torna-se problemática em função dos níveis de águas profundas.

Uma vez que a Política Nacional dos Recursos Hídricos Lei no 10.350/94 estabelece a Bacia Hidrográfica como unidade de gestão dos recursos hídricos. Considera-se que uma bacia sedimentar, uma província hidrogeológica ou um aqüífero, pode ocupar a área de uma bacia hidrográfica, ou de várias bacias, ou ainda de um estado, ou um país. Torna-se necessário o uso de conceitos hidrogeológicos associados a sua cartografia em Sistemas de Informações Geográficas.

\footnotetext{
${ }^{2}$ Dados do Projeto SAG;
} 


\section{METODOLOGIA}

A metodologia desta pesquisa conta com a criação e atualização de um amplo banco de dados dos poços existentes no município de Santa Rosa-RS sendo que é através deste que ocorrerão as etapas de construção do conhecimento ao longo da pesquisa. Foi realizada uma revisão teórico-metodológica, com a consulta a bibliografias pré-existentes referentes ao assunto, além de realizar um trabalho conjunto de troca de informações junto à Prefeitura Municipal de Santa Rosa, em especial a Secretaria de Agropecuária, e também à empresa FORMOBRA que forneceu dados referentes à localização e análises químicas de poços tubulares no município.

A pesquisa foi realizada a partir de dados primários e de dados pré-existentes disponíveis no sítio do SIAGAS/CPRM (Sistema de Informações de Águas Subterrâneas da Companhia de Pesquisas de Recursos Minerais).

Em cada poço foram obtidas as coordenadas em Sistema Universal Transversa de Mercator/UTM em Datum Horizontal SAD-69 e Datum Vertical Porto de Imbituba/SC. Utilizou-se a carta topográfica do município de Santa Rosa na escala 1:50.000 para conferir as observações em campo relativas a localidade e altimetria.

Juntamente com um técnico representante da Secretaria de Agropecuária da Prefeitura Municipal, foi realizado um trabalho de campo, onde foi verificado o estado de conservação dos poços do município, e foram realizadas coletas de amostras de água dos seguintes parâmetros:

- Condutividade Elétrica (C.E.): Determinada pela presença de substâncias dissolvidas que se separam em ânions e cátions, este parâmetro revela a capacidade da água em transmitir a corrente elétrica. Devido a relação proporcional de sólidos totais dissolvidos e a condutividade elétrica pode-se, através deste parâmetro, estipular o teor de sais da água, esse parâmetro foi medido utilizando-se um condutivímetro Hanna HI 93.000.

- Potencial Hidrogeniônico (pH): Caracteriza a medida de concentração de íons $\mathrm{H}^{+}$ (hidrogênio) na água. O equilíbrio entre os íons de hidrogênio e hidróxido determina se a água apresenta caráter ácido ou básico.

Em águas puras os íons $\mathrm{H}^{+}$estão em equilíbrio com os íons hidróxido e seu pH é neutro. $\mathrm{A}$ escala varia de 1 a 14, de ácida à básica, sendo 7 correspondente a pH neutro, o parâmetro de $\mathrm{pH}$ foi medido utilizando-se medidor de $\mathrm{pH}$ Horiba D-55. 
- Sólidos Totais Dissolvidos (STD): Refere-se à matéria sólida em suspensão na água e que pode ser separada por decantação ou filtração. Os altos níveis deste parâmetro podem ocasionar problemas de sabor, efeitos fisiológicos e corrosão. Obteve-se o valor dos sólidos totais dissolvidos multiplicando-se o valor da condutividade elétrica expressa em $(\mu \mathrm{S} / \mathrm{cm})$ pelo valor 0,65 , resultando numa concentração em $(\mathrm{mg} / \mathrm{L})$. Utilizou-se este valor com base em Feitosa e Manoel Filho (1997, p. 90), “(...) Na maioria das águas subterrâneas naturais, a condutividade elétrica da água multiplicada por um fator, que varia entre 0,55 e 0,75, gera uma boa estimativa dos sólidos totais dissolvidos na água". Assim, fez-se a média entre os fatores recomendados pelos autores citados, estabelecendo-se para o presente estudo o valor 0,65 .

- Temperatura: Esta se caracteriza por revelar a possibilidade de aumento de processos químicos na água e pode servir como indicador de profundidade de aqüíferos. A temperatura foi medida utilizando-se um termômetro manual.

Realizadas estas análises os resultados foram espacializados na forma de cartogramas, diagramas e mapas temáticos confeccionados nos programas SPRING 4.3, SURFER 8.0 e AQUACHEM. Os dois primeiros foram responsáveis pela representação da área de estudos, onde foram inseridos os poços obedecendo a suas coordenadas UTM coletadas em campo, e ainda pela representação gráfica da classificação dos parâmetros analisados. O programa AQUACHEM ocupou a função de classificar os principais cátions e ânions das águas coletadas e analisadas compondo uma espacialização na forma de diagramas que revelam os tipos de água (watertypes) e sua tendência a alterações, através de Diagramas de Piper. Este programa transforma as concentrações em miliequivalentes/grama. O Diagrama de Piper é, utilizado para classificação e comparação de distintos grupos de águas quanto aos cátions principais $\left(\mathrm{Ca}^{2+}, \mathrm{Mg}^{+2}, \mathrm{Na}^{+}+\mathrm{K}^{+}\right)$e ânions principais $\left(\mathrm{HCO}_{3}, \mathrm{Cl}^{-}, \mathrm{SO}_{4}{ }^{2-}\right)$ em dois diagramas triangulares respectivos, e combinando as informações dos dois triângulos em um losango situado entre os mesmos (Lucena et al., 2004).

Para a confecção dos mapas, foram utilizados os mapas bases do plano diretor do município e para as pesquisas de campo realizadas através de um levantamento cadastral dos poços tubulares, foi utilizado um receptor GPS (Global Position System), com os mesmos datum do SIAGAS.

A partir destas fontes, foram coletadas informações necessárias para a montagem de um Banco de Dados georreferenciado, tais como: identificação do poço, coordenadas UTM, 
profundidade da perfuração, localidade, situação de uso, tipo de aqüífero, formação geológica, tipo de poço e nível estático dos poços.

Em seguida, esse banco de dados foi integrado aos poços espacializados no mapa base do município de Santa Rosa, com a utilização do programa computacional Spring 4.3.

A espacialização das análises químicas das amostras, assim como da superfície potenciométrica, e a direção de fluxos de águas subterrâneas foram espacializados através de cartogramas do aplicativo computacional Surfer 8.0 onde foram inseridas as Coordenadas UTM de cada poço nas colunas A e B, e o dado a ser analisado na coluna C. A partir da análise das informações, foi utilizado o método de estimação espacial Krigagem, que foi o método que apresentou melhores resultados, e um preenchimento total do mapa sem vazios de informação. Segundo Landim (2000) a krigagem usa informações a partir do variograma para encontrar pesos ótimos a serem associados às amostras com valores conhecidos que irão estimar pontos desconhecidos. Embora o objetivo do trabalho não seja analisar esses métodos, sugere-se para trabalhos futuros realizar uma comparação entre os diversos métodos de análise estatística.

Os trabalhos de campo foram realizados com um veículo disponibilizado pela Prefeitura Municipal de Santa Rosa, que também forneceu um motorista e um técnico para acompanhar os trabalhos de campo. Os aparelhos utilizados são de propriedade do Laboratório de Hidrogeologia da UFSM. Os resultados físico-químicos obtidos foram comparados com os padrões de potabilidade da água para o consumo humano, conforme a Portaria 518/2004 do Ministério da Saúde. Utilizou-se uma câmera digital para obtenção de imagens no campo, indicativas da condição atual de captação, conforme previsto no Decreto Estadual no42.047/2002.

As informações de qualidade da água são de uso restrito da empresa FORMOBRA e não serão apresentados no texto.

A última etapa consistiu na combinação das informações e descrição das características principais das águas subterrâneas bem como seus usos.

Em seguida foi realizada a análise dos resultados e discussões das informações, e por fim as considerações finais e sugestões. 


\section{RESULTADOS E DISCUSSÕES}

Como principal resultado foi confeccionado um banco de dados de poços tubulares localizados no município de Santa Rosa-RS, e diversos produtos cartográficos que espacializaram os dados obtidos em Sistemas de Informações Geográficas/SIG.

Foram obtidos dados de diversas captações de água, 35 poços foram cadastrados a partir de trabalhos de campo, juntamente com a Prefeitura Municipal. Estas captações estão localizadas no interior do município de Santa Rosa e abastecem as pequenas comunidades rurais. A partir do sítio do SIAGAS foram obtidos dados sobre 19 poços tubulares, e pela empresa FORMOBRA, foram fornecidas análises químicas completas de 7 poços, e ainda perfis construtivos de 31 outros poços.

Pôde-se verificar que diversos poços localizados no município estavam sob condições impróprias de uso, devido ao seu estado de conservação, entre outras condições analisadas, as tubulações de 4 poços apresentavam vazamentos o que acarreta num desperdício de água, e o crescimento de microorganismos que podem liberar substâncias nocivas à saúde dos usuários.

Outro problema identificado foi o selo sanitário desgastado em 3 outros poços o que pode proporcionar graves danos ao aqüífero, já que um poço com o selo sanitário danificado consiste num ponto potencial de contaminação, através de precipitações meteóricas, podendo infiltrar água da chuva com contaminantes oriundos da Superfície do terreno, Conforme Norma ABNT/NBR 12.244/2006, a laje em concreto deve apresentar área de no mínimo $1 \mathrm{~m}^{2}$ e $10 \mathrm{~cm}$ de espessura. Ainda observando-se os perfis construtivos pode-se notar a pequena dimensão do selo sanitário interno em concreto. Sua função é proteger a qualidade da água captada evitando que ocorram infiltrações oriundas de usos antrópicos na superfície do terreno. $^{3}$

Outro problema identificado é o fato da maioria dos poços não estarem equipados com o tubo-guia, o que não permite a medição do nível da água subterrânea ${ }^{4}$, previsto no decreto $n^{\circ} 42.047 / 2002$, Art. 30, sendo que apenas 3 poços o possuíam. Um deles devido ao fato de não estar "tampado" com um "cap" que consiste num plástico protetor, poderia acarretar num ponto de contaminação por agentes da superfície, permitindo inclusive a entrada de insetos.

\footnotetext{
${ }^{3}$ Informação verbal do orientador de pesquisa.

${ }^{4}$ Realizada através da introdução de um cabo sonoro (freatímetro) até o nível da água.
} 


\section{Poços tubulares localizados no Sistema Aqüífero Serra Geral}

A faixa de variação do $\mathrm{pH}$ foi entre 3,00 e 12,80 em 35 poços analisados com esta informação, dois dos poços analisados possuíam pH básico com valor acima de 9,50 que é o valor máximo permissível para consumo humano segundo a portaria no 518/2004 do Ministério da Saúde. Outros sete poços possuíam pH ácido com valores abaixo de 6,00, o qual é o valor mínimo permissível segundo a mesma portaria, portanto fora das normas para uso humano em relação a este parâmetro.

\section{Espacialização dos valores de $\mathrm{pH}$ no município de Santa Rosa-RS}

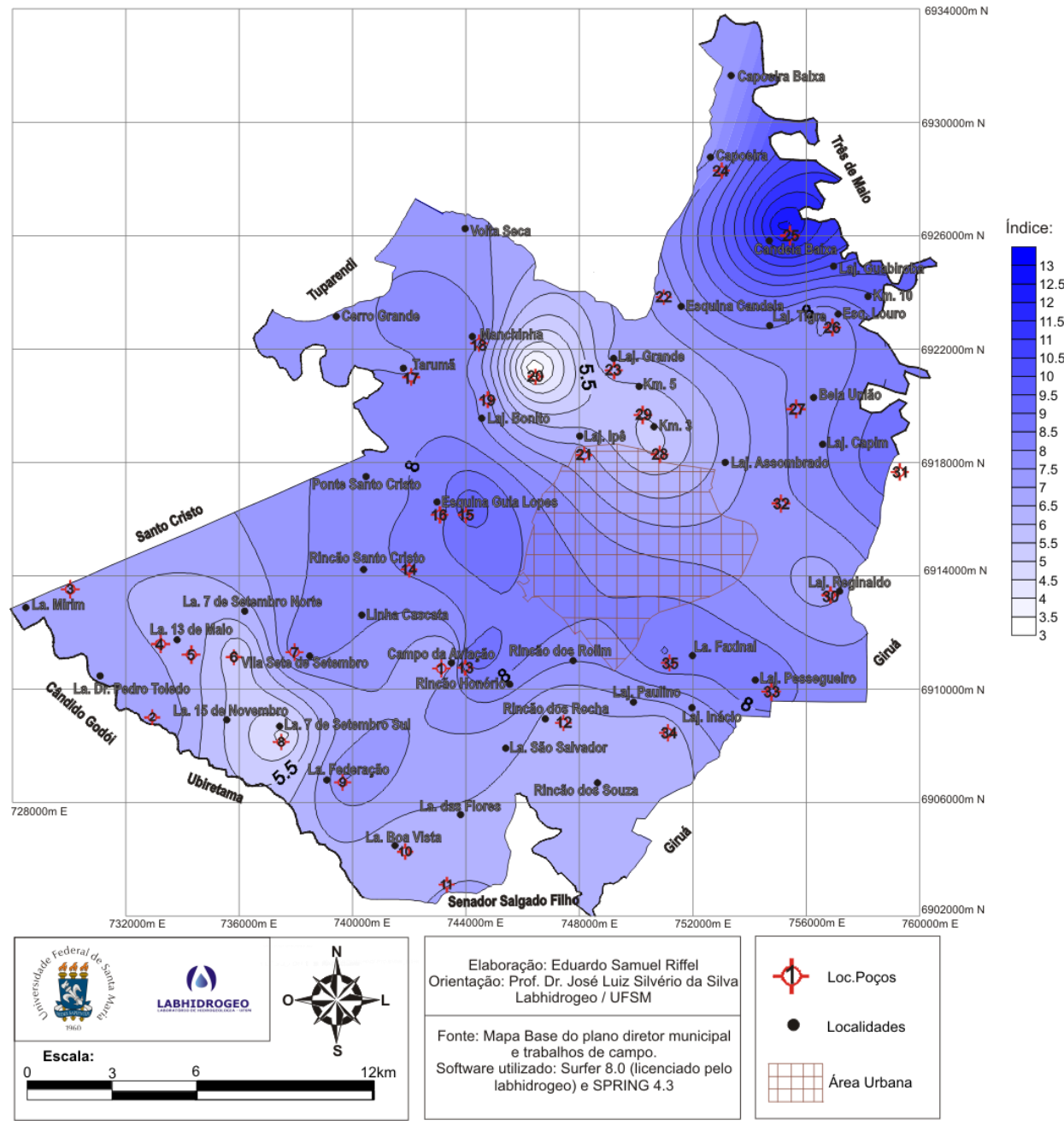

Figura 2- Espacialização dos dados de pH.

Observando-se o cartograma da figura 2 de espacialização dos valores de $\mathrm{pH}$ percebe-se uma homogeneização dos valores das amostras, sendo que apenas um poço localizado em Candeia Baixa no setor nordeste do município, apresenta um valor muito acima dos padrões 
para consumo humano. Valores muito altos de $\mathrm{pH}$ podem contribuir para a corrosão das estruturas das instalações hidráulicas sendo que águas ácidas são corrosivas, podendo também adicionar metais à água tais como: ferro, cobre, chumbo e cádmio. No caso de ser realizado um tratamento da água, a eficiência da cloração também diminui com valores acima de 8,0. Outra dificuldade nesses níveis de água verificada para os usuários na agricultura, principalmente relacionado ao plantio de soja, consiste na dificuldade de se concentrar produtos fertilizantes na água, visto que a maioria das comunidades rurais utilizam apenas águas subterrâneas, inclusive para a agricultura, e determinadas marcas de fertilizantes exigem um pH neutro, ou seja, próximo de 7,00 para que os resultados sejam mais eficientes. Sendo assim, caso haja necessidade de se utilizar um fertilizante no solo, algumas localidades poderão apresentar dificuldades em relação à sua aplicação devido aos níveis de $\mathrm{pH}$ das águas subterrâneas. Sugere-se que seja realizado um tratamento e ajuste do $\mathrm{pH}$ para a obtenção de bons resultados nas colheitas.

A Condutividade Elétrica representa a capacidade de uma água conduzir a Corrente Elétrica. Depende das concentrações iônicas, da temperatura e indica a quantidade de sais existentes na água, pode, portanto ser um indicador da existência de contaminantes na água, como pode também ser um indicador de altas concentrações de elementos dissolvidos na água. Percebe-se na espacialização que os valores de Condutividade Elétrica, acompanham os níveis de pH e STD, tendo suas maiores concentrações nas porções nordeste (Candeia Baixa), oeste (La. Sete de Setembro) e na área urbana do município. A partir disso, pode-se perceber as modificações na composição da água, especialmente na sua concentração mineral, o que é comprovado também pelas análises químicas. Na figura 3 estão espacializadas as concentrações de Condutividade Elétrica no município.

Os valores de Sólidos Totais Dissolvidos (figura 4) também foram em sua maioria homogêneos sendo apenas quatro amostras que apresentaram valores próximos de 500 $\mathrm{mg} / \mathrm{L}$ e uma amostra que apresentou valor acima de $500 \mathrm{mg} / \mathrm{L}$ que é a mesma amostra com valor elevado de pH, localizada em Candeia Baixa. Um valor elevado de concentração de STD pode prejudicar os consumidores das águas, e ocasionar efeitos fisiológicos como não eliminar a sede. Isso devido à quantidade de elementos dissolvidos na água constituídos principalmente por cloretos, sulfatos, fosfatos, nitratos de cálcio, magnésio, etc. 


\section{Espacialização dos valores de Condutividade Elétrica no município de Santa Rosa-RS}

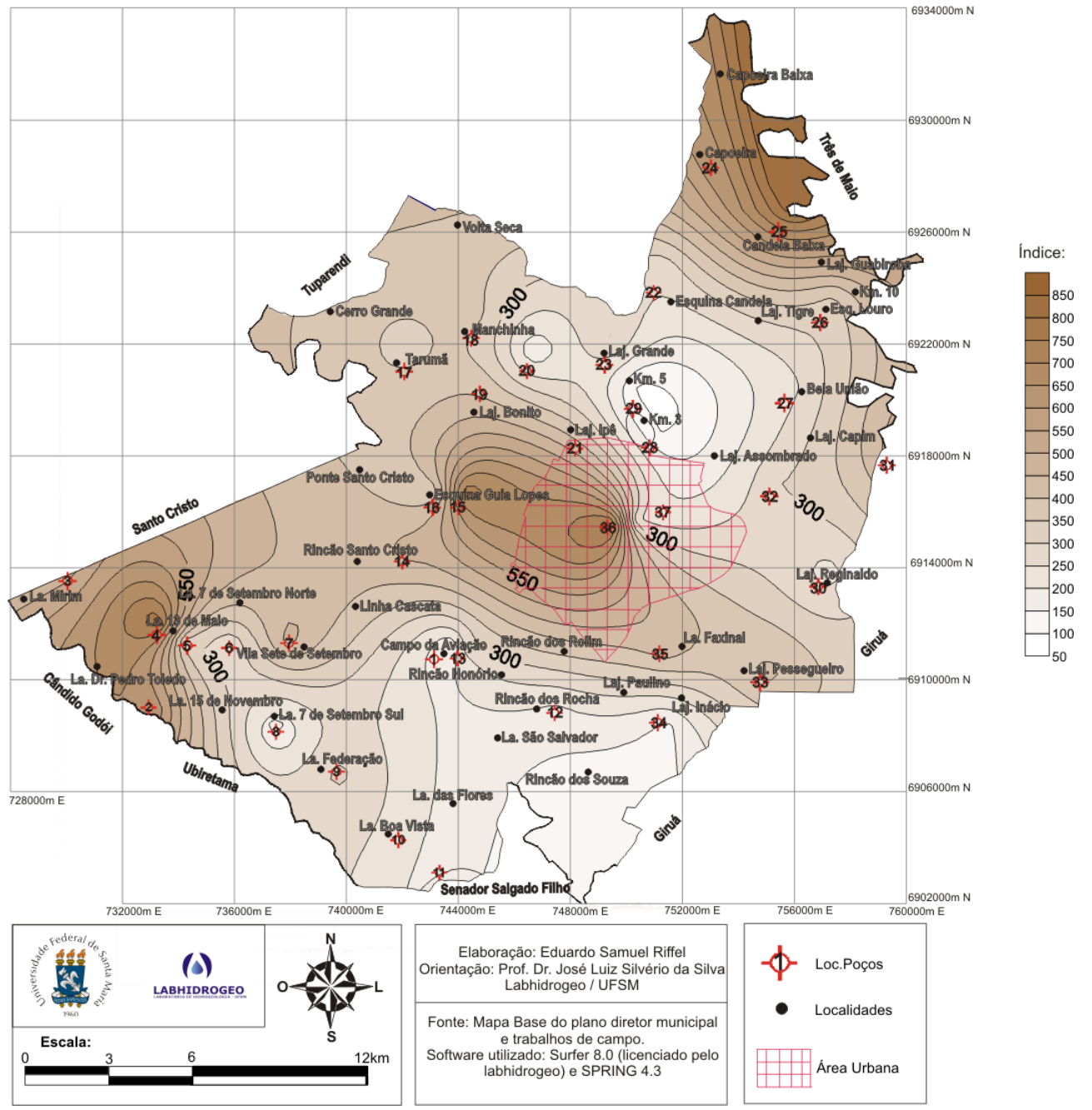

Figura 3 - Espacialização dos valores de Condutividade Elétrica.

Segundo moradores de Candeia Baixa que consomem a água, ela apresenta um aspecto "pesado" e "gorduroso", dificultando nos trabalhos domésticos e com o uso cria uma camada branca rígida dentro dos materiais de alumínio, como panelas e chaleiras, tornandose inutilizável. Isso ocorre devido aos elementos presentes na água, que corroem os utensílios domésticos. Não foi realizada nenhuma análise química desta água, mas acreditase que isto ocorra devido a ocorrência de carbonatos $(\mathrm{pH}>8,2)$ e de bicarbonatos.

Na figura 5 está espacializada a superfície potenciométrica das águas subterrâneas que se obteve a partir do Nível Estático do poço tubular subtraído da cota do terreno (altitude N.E.). Os dados foram obtidos no sitio do SIAGAS e representam uma avaliação da tendência de fluxos das águas subterrâneas, o que representa um conhecimento fundamental no caso 
de contaminação do aqüífero, pois indica o possível trajeto do material contaminante, indicando quais áreas devem ser realizadas ações de contaminação.

\section{Espacialização dos valores de STD no município de Santa Rosa-RS}

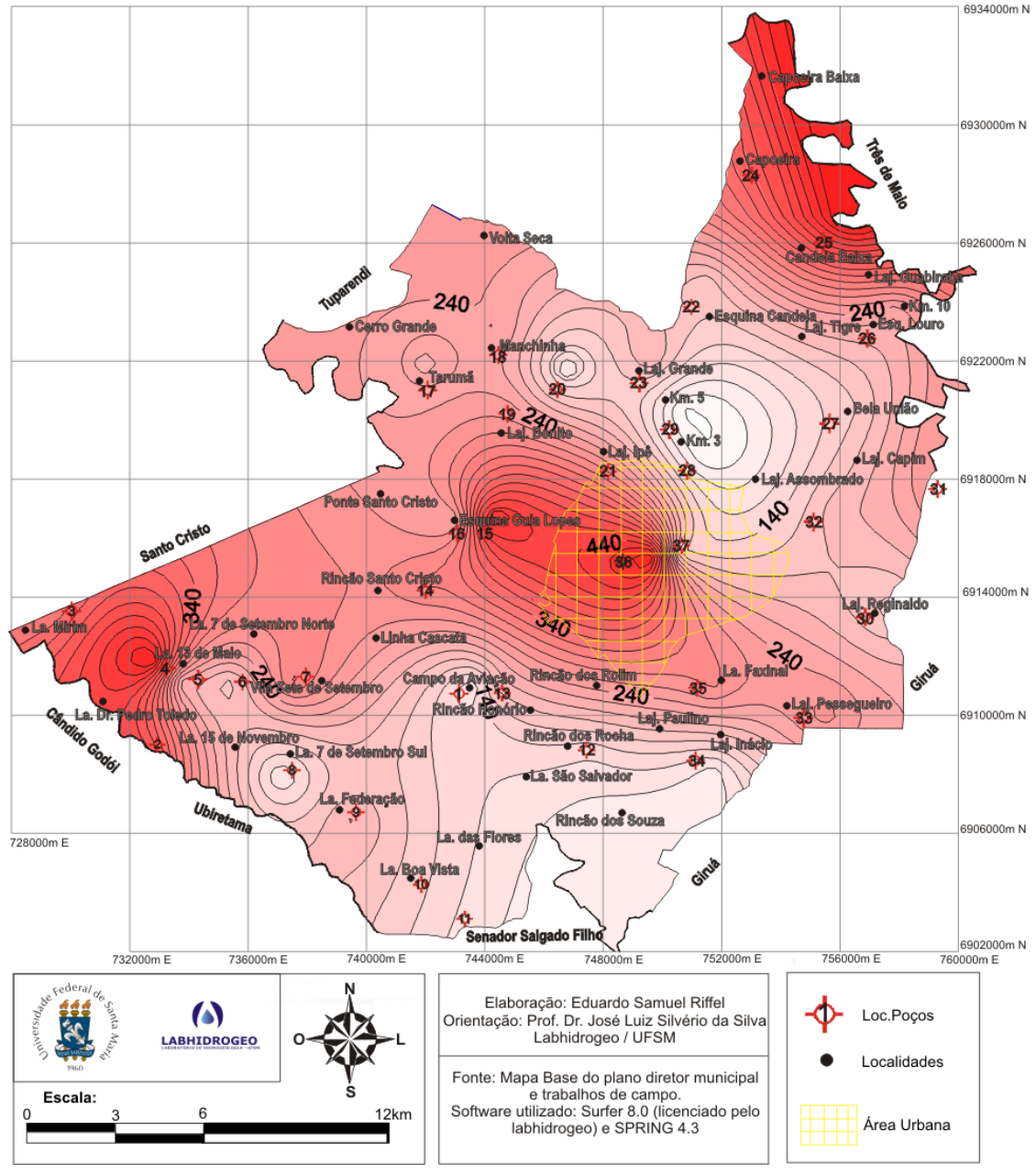

Figura 4 - Espacialização dos valores de STD.

Percebe-se no cartograma que a direção de fluxos ocorre para a direção centro-norte, onde tem a maior ocorrência de pontos de captação de águas subterrâneas na área analisada, além do menor nível da superfície potenciométrica, onde provavelmente ocorrem os maiores volumes de captação de águas subterrâneas.

Devido à carência de dados não se pode obter informações suficientes para todo o município, pois os poços onde foram realizados os trabalhos de campo, não apresentavam tubo-guia, por isso, não foi possível realizar as medições de nível, sendo que os dados disponíveis foram extraídos do sítio do SIAGAS. 


\section{Espacialização da superfície potenciométrica e direção de fluxos de águas subterrâneas em Santa Rosa-RS}

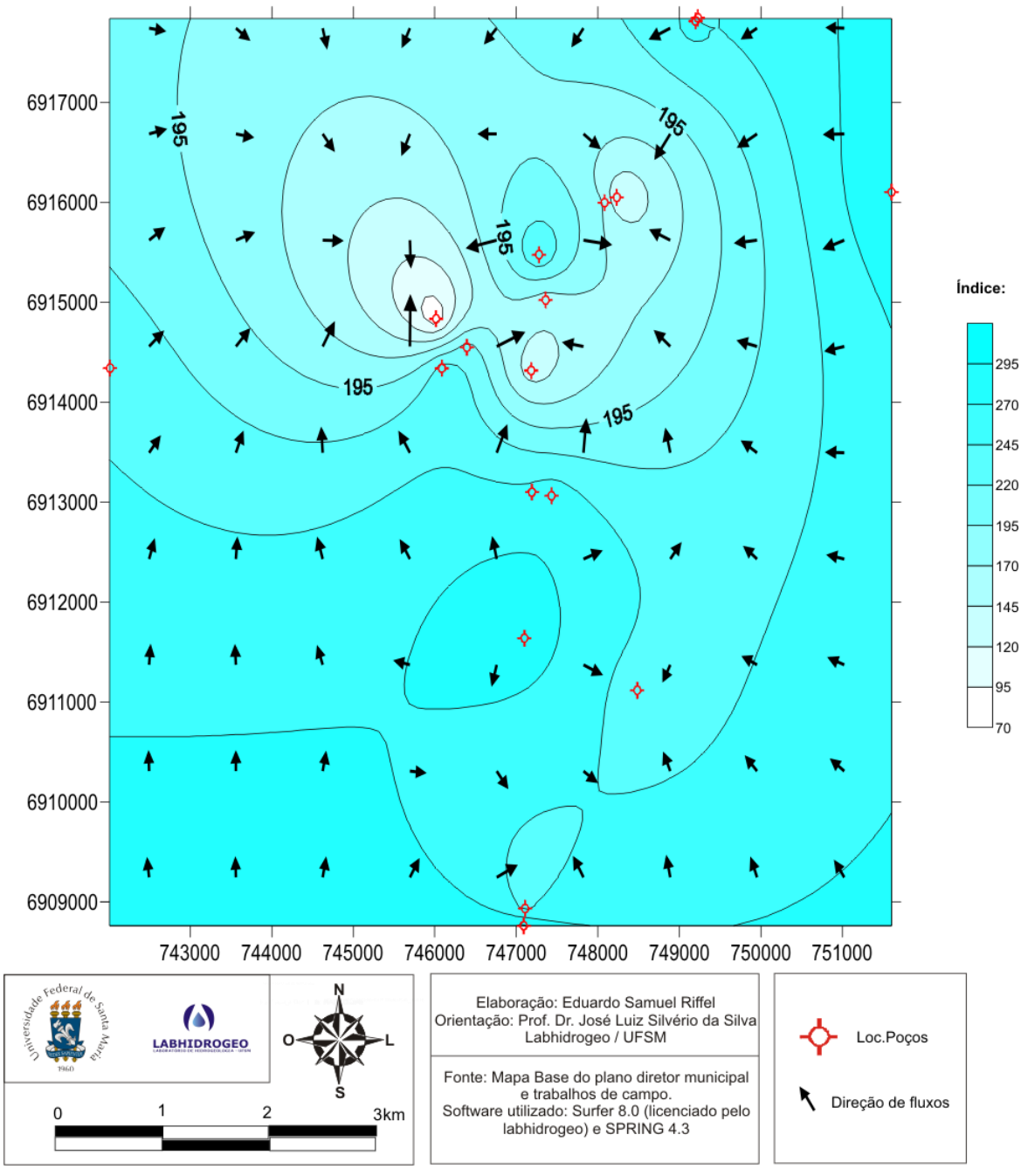

Figura 5 - Espacialização da Superfície Potenciométrica e direção dos fluxos de águas subterrâneas.

\section{Poço tubular localizado no Sistema Aqüífero Guarani}

No município de Santa Rosa está localizado o mais profundo ponto de captação de águas subterrâneas do estado do Rio Grande do Sul, nas dependências de uma empresa Frigorífica. Ele se situa nas coordenadas $27^{\circ} 55^{\prime} \mathrm{S}$ e $54935^{\prime} \mathrm{W}$, possui uma profundidade de $1.220 \mathrm{~m}$, e está cotado no terreno em $280 \mathrm{~m}$.

Esta captação penetrou uma litologia caracterizada por solo e basalto alterado nos primeiros 24 metros, até os 1.115 m ocorre basicamente a Formação Serra Geral, e a partir dos 1.115 metros atinge o Aqüífero Guarani, através da Formação Botucatu (CORNER, 1995).

Em relação aos parâmetros físico-químicos, está de acordo com os parâmetros da Portaria no 518/2004, exceto no flúor, que estava acima do nível permitido para consumo humano, quando da realização da coleta em julho de 2005. Salienta-se que este não representa risco, 
devido ao fato de a água extraída não ser utilizada para consumo humano, apenas para fins industriais, como limpeza e pré-aquecimento de caldeiras, devido ao fato de apresentar uma temperatura elevada, em torno de $42^{\circ} \mathrm{C}$, enquadrada segundo o DNPM (1945) como fonte hipotermal, pois sua temperatura está acima de 38ㄷ․ Segundo OEA (2009), a temperatura das águas do SAG aumenta em função do incremento da profundidade do teto do SAG, na maior parte da sua área confinada, a temperatura varia de 35ㅇ a 55으.

O poço possui um nível estático de $168,50 \mathrm{~m}$ e um nível dinâmico de 192, 70 m, com uma vazão alta, de $113 \mathrm{~m}^{3} / \mathrm{h}$. (CORNER, 2005)

\section{Qualidade e usos das águas subterrâneas no município}

Devido ao fato da maioria das análises químicas obtidas pertencerem a poços tubulares particulares, foi solicitado que os dados de análise química não fossem divulgados, portanto os dados foram utilizados apenas para a espacialização dos dados. A partir dessas análises químicas das águas pode-se constatar que a maioria das amostras de águas encontra-se dentro dos padrões de potabilidade para consumo humano, segundo a portaria $\mathrm{n}$ ㅇ 518/2004, com exceção de dois poços tubulares do Sistema Aqüífero Serra Geral que apresentaram quantidades altas de coliformes totais, acima de 15 UFC/100 mL. Também o poço tubular profundo, que possui elevados teores de flúor, acima do permitido pela mesma portaria.

O resultado das análises de oito amostras dos íons maiores, estão apresentados no gráfico da figura 06 que apresenta um diagrama de Piper construído para obter-se a classificação das águas quanto aos íons predominantes, com sete mostras do Sistema Aqüífero Serra Geral, e uma amostra do Sistema Aqüífero Guarani. O diagrama mostra que as águas dos poços são predominantemente sódicas-bicarbonatadas.

Percebe-se a partir do Diagrama de Piper que a maior parte das amostras é do tipo $\mathrm{Na}-\mathrm{HCO}_{3}$, sendo que a existência predominante de bicarbonatos pode indicar um maior contato das águas subterrâneas com organismos, devido ao fato da presença do $\mathrm{CO}_{3}^{2-}$ que possivelmente pode estar relacionado a fotossíntese, a respiração na zona da biosfera. Além do fato de possuírem em média uma menor profundidade, ocorre mais rapidamente a recarga por águas meteóricas, e isso acarreta possivelmente numa mistura de águas, o que significa chegada de águas novas, o que dá a característica de água bicarbonatada. 


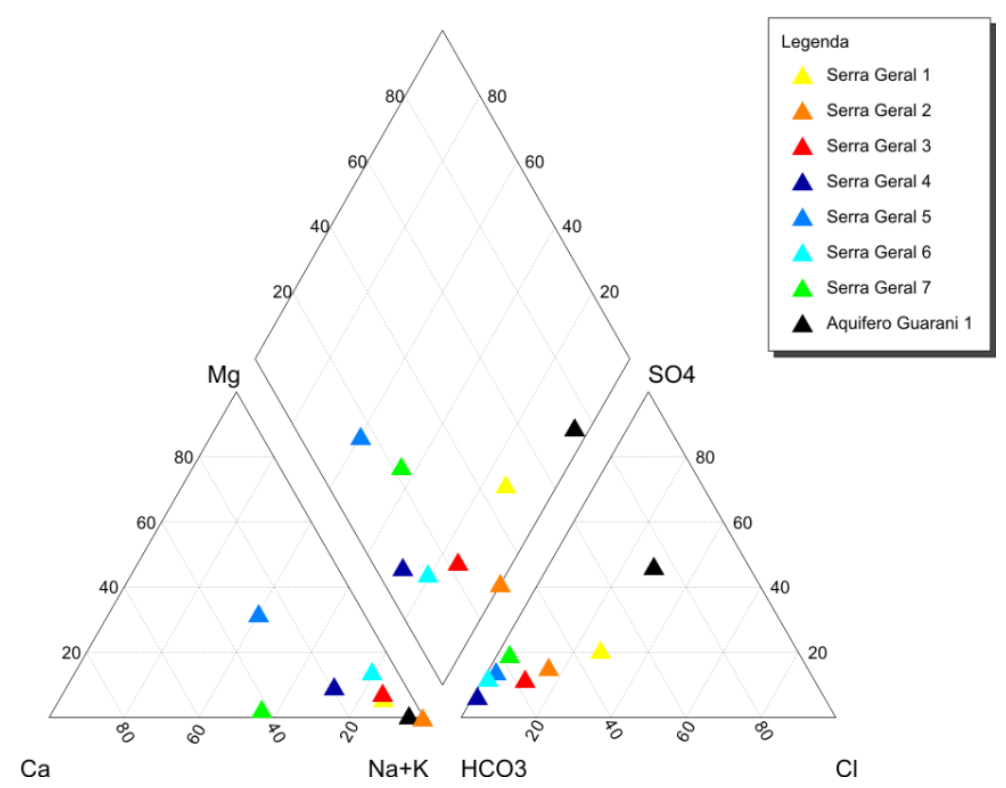

Figura 6 - Diagrama de Piper de amostras de águas subterrâneas de Santa Rosa. Org: RIFFEL, E. S.

Na amostra do poço localizado no Sistema Aqüífero Guarani percebe-se uma menor concentração de $\mathrm{HCO}_{3}^{-}$, e uma maior concentração de $\mathrm{SO}_{4}^{2-}$, o que pode indicar processos ligados não a organismos vivos, mas sim á dissolução de rochas pelo contato prolongado das águas subterrâneas com as mesmas, fato esse devido também a profundidade do poço, e ao seu grau de confinamento. De acordo com Costa (1965 apud Feitosa e Manuel Filho, 1997) os íons $\mathrm{Na}^{+}$e $\mathrm{Ca}^{2+}$ podem provir de plagioclásios. Citam ainda que o conteúdo de $\mathrm{Cl}^{-}$e $\mathrm{SO}_{-4}^{2}$ nas rochas ígneas é em geral muito baixo e conseqüentemente, também é baixo nas águas destas rochas. Em casos particulares, na presença de pirita $\left(\mathrm{FeS}^{2}\right)$, e em meio oxidante os cristais de pirita podem gerar uma quantidade substancial do íon sulfato. Estudos desta natureza estão em realização pelo Laboratório de Hidrogeologia da Universidade Federal de Santa Maria.

Em relação aos usos das águas subterrâneas no município, verificou-se que os quatro usos principais são: consumo humano, uso industrial, lazer e agricultura. Ressalta-se que os poços alocados são apenas aqueles identificados nos trabalhos de campo e no SIAGAS, considerando também que alguns dos poços atendem a mais de um uso, como é o caso dos poços localizados no interior do município, que atendem ao uso da agricultura e ao consumo humano. Conforme quadro 2: 


\begin{tabular}{|c|c|}
\hline Uso & Quantidade de poços \\
\hline Consumo Humano & 45 \\
\hline Uso industrial & 12 \\
\hline Lazer & 2 \\
\hline Agricultura & 40 \\
\hline
\end{tabular}

Quadro 2 - Usos das águas subterrâneas em Santa Rosa. Fonte: SIAGAS e Trabalhos de campo.

Dos diferentes usos de águas subterrâneas no município de Santa Rosa o principal é o consumo humano, que ocorre através da CORSAN no bairro Cruzeiro e pela prefeitura municipal em todas as comunidades rurais do município que totalizam 35 , as quais utilizam as águas também para a agricultura, principalmente cultivo de soja.

Para uso industrial têm-se quatro empresas localizadas no município, a Alibem alimentos possui sete poços, sendo um deles de águas termais, a empresa produz principalmente rações, embutidos, e produtos frigoríficos. A empresa Camera agroalimentos produz óleos de cozinha e possui dois poços tubulares. A Dupont do Brasil, processa sementes da marca Pioneer e possui dois poços tubulares. A empresa AGCO do Brasil produz máquinas agrícolas de grande porte, e também possui dois poços tubulares.

Dois poços tubulares no município são para lazer, sendo eles o da Sociedade Atlética Vigor, e o da Associação de Policiais Civis.

\section{CONCLUSÃO E RECOMENDAÇÕES FINAIS}

Verificou-se que a maior parte das amostras de águas subterrâneas localizadas no município de Santa Rosa no estado do Rio Grande do Sul, na bacia do Paraná, explotados principalmente do Sistema Aqüífero Serra Geral e secundariamente de uma captação termal profunda do Sistema Aqüífero Guarani confinado. Estão dentro dos padrões de potabilidade, ocorrendo apenas alguns pontos isolados com valores considerados impróprios para consumo humano segundo a portaria no 518/2004, os quais devem ser monitorados constantemente. Este procedimento de verificar anomalias nos seus componentes químicos visa a preservação da saúde humana dos consumidores de águas subterrâneas. Caso essas anomalias permaneçam constantes sugere-se alterar o uso das águas de consumo humano para outros fins como na agricultura ou indústria, ou ainda preservar essas águas como reserva futura. Enfim outros usos que não venham a prejudicar a saúde da população futuramente. 
O principal problema identificado consiste no estado de conservação das instalações de alguns poços tubulares executadas fora das normas técnicas da ABNT/NBR 12.212 e 12.244/2006, o que pode torná-los pontos potenciais de contaminação do aqüífero, e isso requer uma maior atenção por parte das autoridades municipais. Visto que na ocorrência de uma eventual contaminação, a sua descontaminação se torna muito difícil e onerosa, e menos viável do que a execução de estudos prévios que venham a identificar a situação dos poços e sua conservação no município.

Os problemas relacionados à contaminação dos lençóis subterrâneos são recentes no país, e já ocorrem em alguns pontos isolados. As medidas de utilização adequada desse recurso hídrico devem ser mais bem estudadas e implantadas de maneira ágil, cabe não somente ao poder público a preocupação com esta fonte de abastecimento de água, mas a atenção da população em exercer práticas impróprias que comprometam o recurso hídrico subterrâneo e a sua própria qualidade de vida, como a conservação dos poços tubulares, pois os problemas quanto à quantidade e qualidade de recursos hídricos não são fatos isolados e estão inseridos em questões globais do meio ambiente.

Considerando a espacialização dos dados em Sistemas de Informações Geográficas das informações obtidas, pode-se averiguar a localização das áreas com valores considerados impróprios para consumo humano segundo as normativas ocorrem principalmente nos setores Nordeste (Candeia Baixa) e Sudoeste (La. Sete de Setembro). A pesquisa é contínua, e o banco de dados deve ser atualizado constantemente para comparação das informações e expansão do mapeamento. Desta forma tem-se uma ferramenta importante que poderá servir de suporte na preservação dos mananciais subterrâneos, bem como subsídios para implantar a gestão e planejamento para as águas subterrâneas no município e na região. Os estudos regionais relacionados às águas subterrâneas ainda são poucos, mas devem ser mais explorados devido à importância das águas subterrâneas para o município de Santa Rosa, principalmente para as comunidades rurais onde o consumo humano de águas subterrâneas é elevado.

No entendimento das diversas etapas metodológicas realizadas neste trabalho, desde a revisão bibliográfica do estado da arte sobre o uso dos recursos hídricos subterrâneos no município, até os contatos com a CORSAN, Prefeitura Municipal, empresa perfuradora de poços FORMOBRA, e pesquisas de campo e SIAGAS, resultaram em um banco de dados. Esse banco de dados poderá servir de suporte a Prefeitura Municipal, sendo que os mapas 
gerados permitirão realizar um diagnóstico do uso atual dos recursos hídricos subterrâneos no município de Santa Rosa.

Os resultados obtidos nesta pesquisa são importantes para o planejamento do município, uma vez que fornecem subsídios para a gestão ambiental no município. Priorizar maior atenção aos recursos hídricos subterrâneos consiste numa sugestão importante e cabível de ser inserida no plano diretor municipal, contribuindo assim, para o planejamento territorial no município e também na manutenção da qualidade dos recursos hídricos subterrâneos para atuais e futuras gerações.

Conclui-se o trabalho utilizando a citação: “A gestão sustentável das águas subterrâneas requer conhecimento cientifico atualizado sobre esse recurso. O conhecimento deve ser transmitido à sociedade, incentivando sua participação e melhorando sua relação com a ciência e a tecnologia." PSAG (2009, pag. 6).

Lembrando-se sempre que este não é um recurso inesgotável e que o velho paradigma deve se quebrado, de que uma água potável é aquela sem cheiro, sem gosto e sem cor. Cabe à universidade realizar a pesquisa, e os resultados retornarem à sociedade para que esta se aproprie destes e use a água de forma racional.

\section{REFERÊNCIAS BIBLIOGRÁFICAS}

AGÊNCIA NACIONAL DE ÁGUAS - ANA. Panorama da qualidade das águas subterrâneas no Brasil. Estudo técnico. Cadernos de Recursos Hídricos. Brasília, 2005.

ASSOCIAÇÃO BRASILEIRA DE ÁGUAS SUBTERRÂNEAS - ABAS. Disponível em: <http://www.abas.org.br> Acesso em: 02 de dezembro de 2009.

BORGHETTI, N. R. B; BORGHETTI, J. R.; ROSA FILHO, E. F. Aqüífero Guarani. A verdadeira integração dos países do MERCOSUL: Curitiba. 2004. 214p.

BRASIL. Decreto no 2.612, de 3 de junho de 1998. Regulamenta o Conselho Nacional de Recursos Hídricos, e dá outras providências. Poder Executivo. Brasília, DF: junho de 1998. . Lei n. 9.433 de 8 de janeiro de 1997. Institui a Política Nacional dos Recursos Hídricos, cria o Sistema de Gerenciamento de Recursos Hídricos. Poder Executivo. Brasília, DF: janeiro de 1997. 
Norma Brasileira no 12244. Construção de poço tubular para captação de água subterrânea. Associação Brasileira de Normas Técnicas. ABNT NBR 12244:2006, 10p.

CARRARO, C. C. GAMERMANN, N. EICK, N. C., BORTOLUZZI, C. A., JOST, H. PINTO, J. F.; Mapa Geológico do estado do Rio Grande do Sul na escala 1:1.000.000. Instituto de Geociências da Universidade Federal do Rio Grande do Sul. Porto Alegre, RS: outubro de 1974.

COMPANHIA DE PESQUISA DE RECURSOS MINERAIS - CPRM. Mapa de Domínios e Subdomínios Hidrogeológicos do Brasil. Sistema de Informações Geográficas Escala 1:2.500.000 CD-ROM, 2007.

Sistema de Informações de Águas Subterrâneas. Disponível no site: <http://www.siagas.cprm.gov.br> Acesso em: 06 de junho de 2009.

CONSELHO NACIONAL DE RECURSOS HÍDRICOS: Conjunto de normas legais / Ministério do Meio Ambiente, Secretaria de Recursos Hídricos e Ambiente Urbano. 5a ed. Brasília: MMA, 2008.

CORNER. Relatório Técnico Final de poço tubular profundo localizado no município de Santa Rosa. Araraquara-SP, setembro de 2005.

EMPRESA BRASILEIRA DE PESQUISA AGROPECUÁRIA. EMBRAPA - Sistema Brasileiro de Classificação de Solos. Disponível em: <http://www.embrapa.br>. Acesso em: 10 de agosto de 2009.

FEITOSA, A. C. F., MANOEL FILHO, J. (Coord.). Hidrogeologia: conceitos e aplicações. CPRM/LABHID. Fortaleza, 1997. 412 p.

FOSTER, S., HIRATA, R. Determinação do risco das águas subterrâneas: um método baseado em dados existentes. São Paulo: Instituto Geológico, 1988.

FUNDAÇÃO DE ECONOMIA E ESTATÍSTICA. Resumo Estatístico do RS - Municípios. Disponível em: <http://www.fee.tche.br/sitefee/pt/content/capa/index.php>. Acesso em: 28 jul. 2009.

GUERRA, A. T., GUERRA, A. J. T. Novo dicionário geológico-geomorfológico. Rio de Janeiro: Bertrand Brasil, 1997. 260 p. 
HAUSMAN, A. Províncias Hidrogeológicas do Rio Grande do Sul. São Leopoldo/RS: Universidade do Vale do Rio dos Sinos, 1995. 125 p.

HIRATA, R. Recursos Hídricos. In: TEIXEIRA, W. et al (orgs.). Decifrando a Terra. São Paulo: Oficina de Textos, 2000.

INSTITUTO BRASILEIRO DE GEOGRAFIA E ESTATÍSTICA. IBGE - Pesquisa de Informações Básicas Municipais. Disponível em: <http://www.ibge.gov.br>. Acesso em: 8 de maio de 2009.

LANDIM, P. M. B. e STURARO, J. R.; Krigagem indicativa aplicada à elaboração de mapas probabilísticos de riscos. DGA,IGCE,UNESP/Rio Claro, Lab. Geomatemática, Texto Didático 06, 19 pp. 2002.

LUCENA, L. F. R.; ROSA FILHO, E. F.; BITTENCOURT, A. V. L., Características hidroquímicas do aqüífero barreiras no âmbito do setor oriental da Bacia do Rio Pirangi - RN. Revista Águas Subterrâneas. Curitiba - PR. v. 18. n. 18. p. 29-38. 2004.

MACHADO, J. L. F.; FREITAS, M. A. Mapa Hidrogeológico do Estado do Rio Grande do Sul. Escala 1:750.000. CPRM: Companhia de Pesquisa de Recursos Minerais. 2005.

MINISTÉRIO DA SAÚDE. Portaria n. 518, de 25 de março de 2004. Atualiza as disposições da Portaria n 1469 de 29 de dezembro de 2000. Brasília, 2004.

ORGANIZAÇÃO DOS ESTADOS AMERICANOS (OEA). Aqüífero Guarani: programa estratégico de ação. Edição bilíngüe. - Brasil; Argentina; Paraguai, Uruguai; Organização dos Estados Americanos (OEA) janeiro de 2009. 424 p.

PREFEITURA MUNICIPAL DE SANTA ROSA. História do município. Disponível em: http://www.santarosa.rs.gov.br>. Acesso em: 06 de junho de 2009.

Plano Diretor Participativo do Município de Santa Rosa - RS.

Disponível no site: <http://www.santarosa.rs.gov.br> Acesso em: 06 de junho de 2009.

REBOUÇAS, A. da. C. et al. Águas Doces no Brasil. Academia Brasileira de Ciências, Instituto de Estudos Avançados da USP. 1999. 
RIO GRANDE DO SUL. Lei n. 11.520 de 03 de agosto de 2000. Código Estadual do Meio Ambiente. Institui o Código Estadual do Meio Ambiente do Estado do Rio Grande do Sul e dá outras providências. 2000 .

SECRETARIA ESTADUAL DO MEIO AMBIENTE. SEMA - Secretaria Estadual do Meio Ambiente. Disponível em <http://www.sema.rs.gov.br>. Acesso em 6 de junho de 2009.

SILVERIO DA SILVA, J. L.; DRESSLER, V. L.; RIFFEL, E. S.; SANTIAGO, M. R. Ocorrências anômalas de flúor em águas subterrâneas do Sistema Aqüífero Guarani no estado do Rio Grande do Sul. Revista Geografia: Ensino e Pesquisa, Santa Maria-RS. Vol. 12, p.623-639, 2008.

TUCCI, C. E. M. (Org.). Hidrologia: ciência e aplicação. Porto Alegre: Ed. Da Universidade: ABRH: EDUSP, 1993.

ZOBY, J. L. G.; MATOS, B. Águas subterrâneas no Brasil e sua inserção na política nacional de recursos hídricos. In: CONGRESSO BRASILEIRO DE ÁGUAS SUBTERRÂNEAS. Florianópolis: Abas, v. 12, 2002.

Artigo recebido em 23/08/2011.

Artigo aceito em 20/09/2011. 